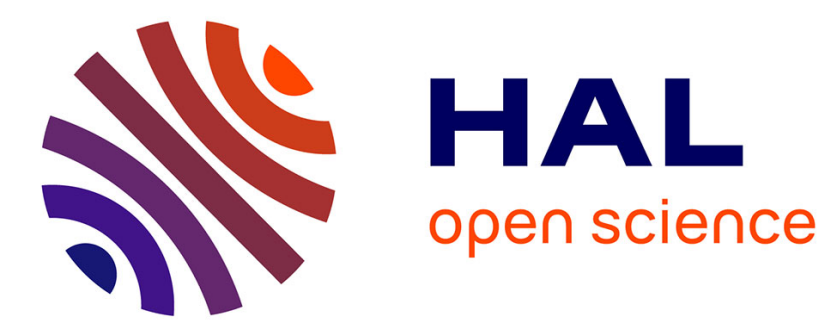

\title{
Electromyogram as an indicator of neuromuscular fatigue during incremental exercise
}

Christine Hanon, C. Thépaut-Mathieu, Christophe Hausswirth, J. M. Le Chevalier

\section{- To cite this version:}

Christine Hanon, C. Thépaut-Mathieu, Christophe Hausswirth, J. M. Le Chevalier. Electromyogram as an indicator of neuromuscular fatigue during incremental exercise. European Journal of Applied Physiology, 1998, 78 (4), pp.315-323. 10.1007/s004210050426 . hal-01623789

\section{HAL Id: hal-01623789 \\ https://hal-insep.archives-ouvertes.fr/hal-01623789}

Submitted on 30 Oct 2017

HAL is a multi-disciplinary open access archive for the deposit and dissemination of scientific research documents, whether they are published or not. The documents may come from teaching and research institutions in France or abroad, or from public or private research centers.
L'archive ouverte pluridisciplinaire HAL, est destinée au dépôt et à la diffusion de documents scientifiques de niveau recherche, publiés ou non, émanant des établissements d'enseignement et de recherche français ou étrangers, des laboratoires publics ou privés. 


\section{Hanon - C. Thépaut-Mathieu - C. Hausswirth J.M. Le Chevalier \\ Electromyogram as an indicator of neuromuscular fatigue during incremental exercise}

Accepted: 16 December 1997

\begin{abstract}
This study analysed the changes in the electromyographic activity (EMG) of the vastus lateralis muscle (VL) during an incremental maximal oxygen uptake test on a treadmill. A breakpoint in the integrated electromyogram (iEMG)-velocity relationship has already been interpreted in two ways: either as a sign of neuromuscular fatigue or as an expression of the iEMG-velocity relationship characteristics. The aim of this study was to test a method of distinguishing fatigue effects from those due to increases in exercise power. Eight well-trained male runners took part in the study. They completed a running protocol consisting of 4-min stages of increments in power output. Between each stage (about $15 \mathrm{~s}$ after the start of a minute at rest), the subjects had to maintain a standard effort: a 10 -s isometric leg extension contraction $[50 \%$ isometric maximal voluntary contraction (IMVC)]. The EMG was recorded during the running and isometric protocols, a change in the EMG signal during the isometric exercise being considered as the sign of fatigue. The iEMG-velocity relationships were strongly fitted by a second-order polynomial function for data taken at both the start $(r=0.98)$ and the end $(r=0.98)$ of the stage. Based on the stability of the $50 \% \mathrm{IMVC}$-iEMG relationship noted between stages, the start-iEMG has been identified as expressing the iEMG-velocity relationship without fatigue. The stage after which end-iEMG increased significantly more steeply than start-iEMG was considered as the iEMG threshold and was simultaneous with the ventilatory equivalent for carbon dioxide threshold. The parallel changes of minute ventilation and iEMG would suggest the existence of common regulation stimuli linked either to effort intensity and/or to meta-
\end{abstract}

C. Hanon $(\triangle) \cdot C$. Thépaut-Mathieu $\cdot$ C. Hausswirth J.M. Le Chevalier

Laboratoire de Biomécanique et de Physiologie - Institut

National du Sport et de l'Education Physique,

11 avenue du Tremblay,

F-75 012 Paris, France bolic conditions. The fall in intracellular $\left[\mathrm{K}^{+}\right]$has been discussed as being one of the main factors in regulating ventilation.

Key words Lactate threshold - Ventilation threshold $\cdot$ Surface electromyography threshold · Treadmill running · Isometric exercise

\section{Introduction}

The transition from aerobic to anaerobic metabolism has been a subject for special focus over the last few decades. During an exercise protocol of incrementing intensity the relationships between exercise intensity and most of the parameters involved [heart rate (HR), expiratory flow $\left(\dot{V}_{\mathrm{E}}\right)$, oxygen uptake $\left(\dot{V} \mathrm{O}_{2}\right)$, lactacidaemia] are linear until a breakpoint which has been considered as an indicator of metabolic change. Thus, Conconi et al. (1982), Davis et al. (1983) and Wasserman (1984) have used HR, lactacidaemia and $\dot{V}_{\mathrm{E}}-\dot{V} \mathrm{O}_{2}$ breakpoints, respectively to determine this metabolic change.

During the last few years a changing pattern of electromyographic (EMG) activity has been associated with this assessment of threshold. These experiments have analysed the integrated EMG (iEMG) and/or the mean power frequency (MPF) of the electromyographic signal. These two parameters are indicators of neuromuscular fatigue. It has been shown that the increase in iEMG reflects a greater motor unit recruitment to maintain the required force level (Enoka and Stuart 1992). The shift in MPF to lower frequencies has been attributed to a decrease in action potential conduction velocity over the muscle (attributable to increased acidity; Hägg 1992).

The EMG threshold has sometimes been detected during the aerobic-anaerobic transition phase at similar intensities to that of the lactate threshold (Viitasalo et al. 1985; Sihvonen et al. 1988). For these authors, the ventilatory threshold was identified at these same exercise power values. 
However, the thresholds for EMG and $\dot{V}_{\mathrm{E}}$ have more often been detected later than that for lactate. When this has been the case, the EMG threshold has occurred either at the same time as (Taylor and Bronks 1994; Mateika and Duffin 1994) or later than (Nagata et al. 1981; Moritani et al. 1993) that for $\dot{V}_{\mathrm{E}}$. Thus, there is a discrepancy in the results although the same muscle has been studied, all authors having chosen to investigate the vastus lateralis muscle (VL). This choice was the same whether the activity tested was cycling or running. This choice has been justified because fatigue thresholds in the quadriceps and triceps surae muscles are not significantly different in both activities (De Vries et al. 1990). The discrepancies in the results obtained by these authors have undoubtedly been due to the variety of experimental protocols (continuous - Nagata et al. 1981; or discontinuous - Moritani et al. 1993) and the diversity of the methods used to determine the different thresholds. Some have used a visual method (Nagata et al. 1981); others have compared slopes which have been calculated using the EMG-exercise intensity relationship (Hélal et al. 1987). Different methods of determination have sometimes been used by the same authors (Taylor and Bronk 1994). Most of the time the detection of thresholds has been from individual data, and as a result the authors have noted problems in detecting a breakpoint (Taylor and Bronks 1994). Authors have also mentioned technical problems encountered in the collection and analysis of the EMG signal (Taylor and Bronks 1995) and intersubject variabilities (Taylor and Bronks 1994; Hélal et al. 1987).

In spite of these difficulties, the EMG threshold has often been determined during an incremental exercise intensity test on the basis of the change in iEMG. However, this parameter can increase in relation to the level of force produced without any metabolic change occurring. Lippold (1952) was the first to identify this phenomenon during isometric contractions. Since then Taylor and Bronks (1995) have also obtained the same results during dynamic contractions. This increase in neural activity occurs during exercise of incremental intensity in response to the need to recruit progressively additional motor units.

However, the relationship between EMG and the force level does not always seem to be linear: a breakpoint has been detected. This can be explained by several different phenomena. Miyashita et al. (1981) have pointed out that muscle groups are involved in different ways according to the running velocity. It should be underlined that velocity increase has been shown to be managed differently by runners who increase the frequency and amplitude of their stride by greater or lesser amounts (Nilsson and Thorstensson 1987). Moreover, during an incremental exercise test, the succession of stages leads progressively to a state of fatigue, which is all the more inevitable since type II fibres are progressively recruited. It has been found that a failure in the fast oxidative glycolytic and fast glycolytic fibres at a certain stage causes an additional recruitment of fibres to meet the level of power required for the test (Enoka and Stuart 1992). The additional fibre recruitment induced by fatigue can also cause a breakpoint in the EMG-exercise intensity relationship.

For all these reasons, an iEMG breakpoint observed during an incremental running test may be due either to the increase in exercise intensity and/or to the onset of neuromuscular fatigue.

The aim of this experiment was to test the subjects in such a way as to detect the effect of fatigue on the EMG signal independently of the effects due to the increase in exercise intensity. That is why an isometric effort (of identical intensity, i.e. $50 \%$ isometric maximal voluntary contraction, IMVC) between each stage was introduced. An increase in this signal would then be considered to be the onset of neuromuscular fatigue. The method used allowed us to determine an EMG breakpoint not for each individual but for a given group of subjects. The breakpoint was detected using a statistical method to minimize the effects of interindividual variations. This same method was used to determine lactate and ventilatory thresholds so that the processing of results could be the same, thus achieving the same sensitivity in the detection of all the thresholds studied.

\section{Methods}

\section{Subjects}

Eight well-trained male subjects took part in this study. They were training regularly five times a week. They had previously been accustomed to treadmill running tests. Their mean age, mass and height were 24.7 (SD 3.8) years, 64.1 (SD 6.4) kg and 175.2 (SD $5.5) \mathrm{cm}$ respectively. Their mean peak $\dot{V} \mathrm{O}_{2}$ was 72.3 (SD $5.1) \mathrm{ml} \cdot \mathrm{min}^{-1} \cdot \mathrm{kg}^{-1}$ and ranged from 63.6 to $78.5 \mathrm{ml} \cdot \mathrm{min}^{-1}$. $\mathrm{kg}^{-1}$.

The subjects were informed of the experiment procedures and gave their written consent before the tests. Prior to the experiment, each subject underwent a general medical checkup.

\section{Experiment protocol}

The test included two types of exercise (Fig. 1):

1. A running protocol performed on a treadmill, consisting of 4-min stages separated by 1 -min rest periods.

2. An isometric protocol consisting of isometric voluntary contractions of the leg extensors performed at the start of the experiment and after each stage of the running protocol.

The ventilatory measurements were made during the last 2 min of each stage of the running protocol while the blood samples were collected after the isometric contractions. The EMG was recorded throughout the experiment (running and isometric protocols).

\section{Isometric protocol}

Isometric leg extensions were performed using a dynamometer (leg extension machine). The subjects were seated in an upright position (angle of hip of $90^{\circ}$ ). Great care was taken to align the flexionextension axis of the knee joint with the axis of the dynamometer. A belt fastened around the pelvis was used to secure the subject in the seat. The movement of the mechanical lever arm was blocked 
Fig. 1 Design of the experiment. Running protocol: vertical bars; isometric protocol: hatched area $B d$ blood samples; $V e n t$. ventilatory samples; $R P E$ rate of perceived exertion (Borg 1970); EMG electromyogram; $S, E$ start and end of stages

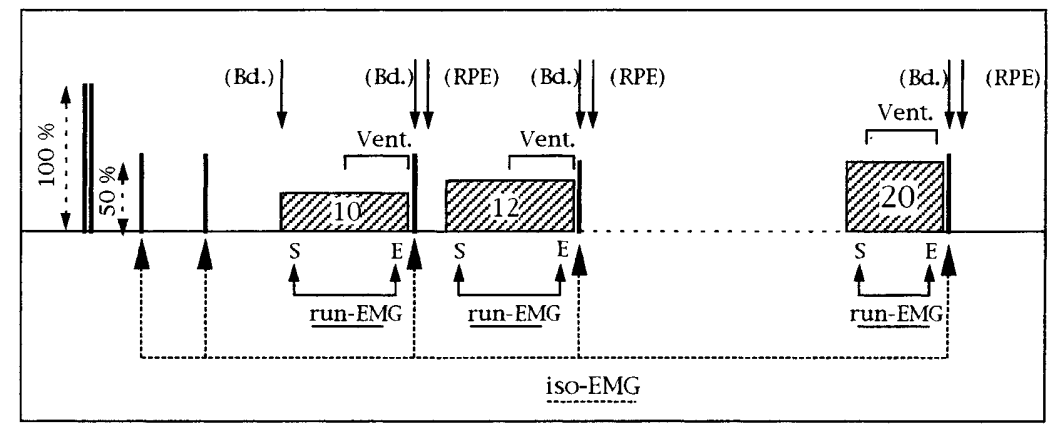

by installing a metal rod that linked this mechanical lever arm to the frame of the dynamometer. No movement was possible and the knee angular position was fixed at $120^{\circ}$ of knee extension $\left(180^{\circ}=\right.$ complete knee extension). Force exerted on the mechanical arm was measured using of a strain gauge mounted on the metal rod.

Before the running protocol the subjects performed two IMVCs of the right knee extensors at an interval of $2 \mathrm{~min}$. Each contraction was maintained for $3 \mathrm{~s}$. The isometric effort used subsequently consisted of $50 \%$ of the better of the two scores of the IMVC ( $50 \%$ IMVC). The subjects were given visual feedback of the torque produced on an oscilloscope and were instructed to maintain the $50 \% \mathrm{IMVC}$ for $10 \mathrm{~s}$. This isometric task was first performed before the running protocol, with 3-min rest between the two protocols, and then at the end of each stage of the running protocol. The mean time elapsed between the end of the stages and the $50 \%$ IMVC was less than $10 \mathrm{~s}$.

\section{Running protocol}

The incremental exercise intensity tests were conducted on a motorized treadmill ( $3 \%$ gradient). The velocity was controlled by an electronic cell placed on the treadmill belt and was increased by $2 \mathrm{~km} \cdot \mathrm{h}^{-1}$ in stages of 4 min until the subject felt exhausted $\left(20 \mathrm{~km} \cdot \mathrm{h}^{-1}\right.$ for all subjects). At the end of each stage the exercise was interrupted for a 1-min rest.

The tests began at a treadmill velocity of $10 \mathrm{~km} \cdot \mathrm{h}^{-1}$ [corresponding to $57 \%$ maximal oxygen uptake $\left(\dot{V} \mathrm{O}_{2 \max }\right)$ for this group]. Before the tests the subjects had to run for $10 \mathrm{~min}$ at a treadmill velocity of $9 \mathrm{~km} \cdot \mathrm{h}^{-1}$ to warm up.

\section{Measurements of respiratory parameters}

The subjects' expired gases were collected on-line during the last 2 min of each stage and analysed using a metabolic measurement cart (CPX, Medical Graphics). The apparatus was calibrated before and after each subject's session by using gases of known concentration. The data were averaged every $10 \mathrm{~s}$ throughout the test. Only data obtained during the last $30 \mathrm{~s}$ of each stage were processed.

In addition to $\dot{V}_{\mathrm{E}}$, the respiratory equivalents of oxygen $\left(\dot{V}_{\mathrm{E}} / \dot{V} \mathrm{O}_{2}\right)$ and carbon dioxide $\left(\dot{V}_{\mathrm{E}} / \dot{V} \mathrm{CO}_{2}\right)$ were determined as has been recommended by Davis (1985).

\section{Blood sampling and lactate analysis}

Immediately at the end of each stage of the treadmill session, a $50-\mu$ blood sample was withdrawn from the earlobe to determine lactate concentration using an automatic enzymatic method (Microzym-L, Inceltech).

EMG sampling and analysis

The EMG signal was picked up from the belly of VL using a bipolar configuration. The skin was scraped to ensure that skin impedance was kept below $1000 \Omega$. A pair of electrodes $(10 \mathrm{~mm}$, $\mathrm{Ag}-\mathrm{AgCl}$, Numeris) was placed parallel to the muscle fibres. The centre-to-centre distance was $20 \mathrm{~mm}$. The differential electrodes were referenced to an earth lead on the tibial tuberosity. The EMG signal was recorded continuously throughout each test, amplified $(\times 600)$, filtered (bandwidth $6 / 1500 \mathrm{~Hz}$, Mazet Electronic) and stored on cassette using a digital audio tape recorder (KMT D-8 Mini type, Sony). The sampling rate was $12 \mathrm{kHz}$ per channel with 12-bit data resolution. Off-line EMG recorded samples were digitized using a $1 \mathrm{kHz}$ sampling rate and stored on computer disk. The EMG was then processed.

\section{Iso-electromyogram}

The EMG signal corresponding to $50 \%$ IMVC was analysed from the 2.5 to $9.5 \mathrm{~s}$ (i.e. over $7 \mathrm{~s}$ ). The first 2.5 and the last $0.5 \mathrm{~s}$ were excluded to eliminate start and stop artefacts in the subject and the instrument (Fig. 2).

This signal was integrated and the value at each second was individually noted. This value was related to iso-iEMG data obtained for the 1st recorded during the first $50 \%$ IMVC performed $3 \mathrm{~min}$ before the running protocol.

A 7-s iso-EMG spectrum analysis (fast Fourier transform, 512 points) was performed on the first 13 windows. From each spectrum, the MPF was calculated.

\section{Run-integrated electromyogram}

The EMG signal recorded during the different running stages was analysed at the start (S) and at the end (E) of each 4-min stage (i.e. five consecutive running bursts were integrated at $20 \mathrm{~s}$ and $3 \mathrm{~min}$ $40 \mathrm{~s}$, respectively). The run-iEMG values were expressed with regard to the burst duration (iEMG/burst duration) and were considered as the measures of muscle activity.

The mean value of the five running bursts was then expressed relative to those obtained at the start of the first stage.

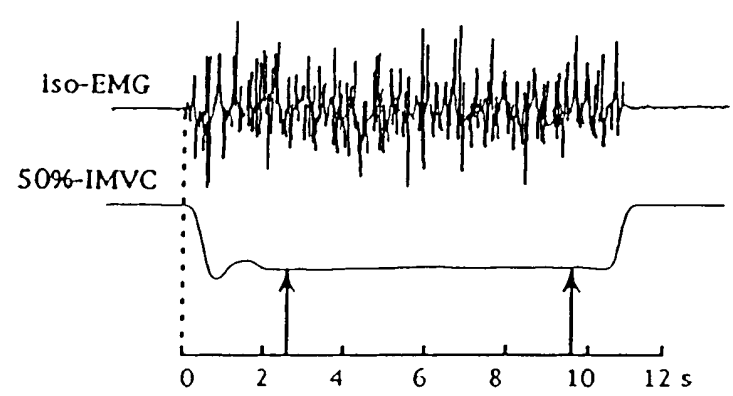

Fig. 2 Electromyogram and force signals recorded during a $50 \%$ isometric maximal voluntary contraction $(I M V C)$. The arrows delimit the window where the EMG data were analysed 


\section{Perceived exertion}

Immediately after each isometric contraction, the subjects were asked to give a rating of perceived exertion (RPE) using Borg's 6/20 point scale (Borg 1970).

\section{Statistics and threshold determination}

Changes in the data compared to changes in treadmill velocity were shown by an analysis of variance for repeated measures. The lactate, ventilatory, RPE and iso-EMG thresholds were assessed from the results of paired Student's $t$-tests including the results of two successive stages (i.e. $10 \mathrm{~km} \cdot \mathrm{h}^{-1}$ vs 12,12 vs $14, \cdots 18$ vs 20 ). The last stage at which there was no significant difference between that and the previous one was considered as the threshold.

The run-iEMG threshold was determined by using paired Student's $t$-tests comparing the run-iEMG values between $\mathrm{S}$ and $\mathrm{E}$ of each successive stage. The last stage where no difference was detected was considered as the run-iEMG threshold.

The changes at $P<0.05$ were considered as significant.

\section{Results}

\section{Lactate concentration}

Figure 3 shows that the last non-significant interstage difference observed in analysing lactacidaemia change during the treadmill session appeared between 12 and $14 \mathrm{~km} \cdot \mathrm{h}^{-1}[2.05$ (SD 0.3) vs 2.6 (SD 0.38) mmo$1 \cdot 1^{-1}$ ]. Therefore, the threshold was determined as being $14 \mathrm{~km} \cdot \mathrm{h}^{-1}$. For this group, the $4-\mathrm{mmol} \cdot \mathrm{l}^{-1}$ threshold (see Mader et al. 1976) was detected at $15.71 \mathrm{~km} \cdot \mathrm{h}^{-1}$.

\section{Ventilatory parameters}

1. $\dot{V}_{\mathrm{E}}-$ No steady state was detected for this parameter. The 10 versus $12 \mathrm{~km}^{-1} \mathrm{~h}^{-1}$ paired Student's $t$-test showed a significant difference. A second-order function $(y=$ $48.7-3.1 x+0.4 x^{2}$ ), where $y=\dot{V}_{\mathrm{E}}$ and $x=$ velocity was significantly correlated $(r=0.99)$.

2. Figure 3 shows $\dot{V}_{\mathrm{E}} / \dot{V} \mathrm{O}_{2}$ was unchanged during the first three stages. The last non-significant difference appeared between 12 and $14 \mathrm{~km} \cdot \mathrm{h}^{-1}$, the $\dot{V}_{\mathrm{E}} / \dot{V} \mathrm{O}_{2}$ threshold therefore being determined at $14 \mathrm{~km} \cdot \mathrm{h}^{-1}$.

3. Figure 3 shows for $\dot{V}_{\mathrm{E}} / \dot{V} \mathrm{CO}_{2}$ that the last non-significant difference appeared between 14 and $16 \mathrm{~km} \cdot \mathrm{h}^{-1}$, the threshold being determined at $16 \mathrm{~km} \cdot \mathrm{h}^{-1}$.

\section{EMG parameters}

\section{Iso-electromyogram}

Iso-integrated electromyogram. The data collected during the $50 \%$ IMVC were analysed in two ways:

1. Intra-contraction: changes in iso-EMG during a contraction were studied to identify the initial sequence of the contraction during which the EMG

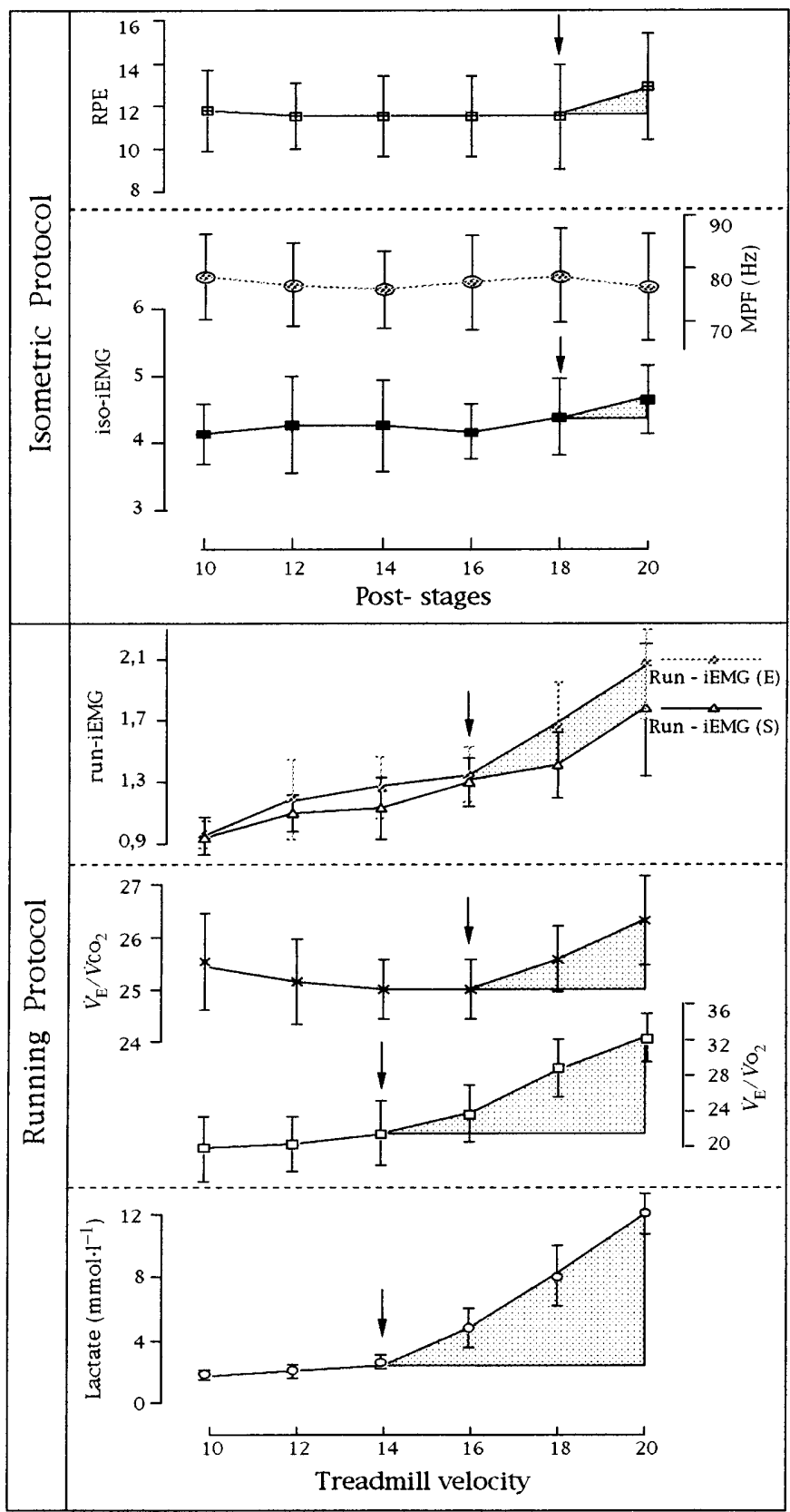

Fig. 3 Threshold chronology observed for metabolic [lactacidaemia, ventilatory equivalents $\left.\left(\dot{V}_{\mathrm{E}} / \dot{V} \mathrm{O}_{2}, \dot{V}_{\mathrm{E}} \dot{V} \mathrm{CO}_{2}\right)\right]$, myoelectrical and psychological (rate of perceived exertion, RPE) parameters during running and isometric protocols (arrows indicate the thresholds). $\dot{V}_{\mathrm{E}}$ Minute ventilation; $V \mathrm{O}_{2}$ oxygen uptake; $V \mathrm{CO}_{2}$ carbon dioxide production; $i E M G$ integrated electromyogram (run-iEMG values were expressed with regard to those obtained at the start of the first stage; iso-iEMG values were related to the iso-EMG obtained for the 1 st s $50 \%$ IMVC performed before the running test); $M P F$ mean power frequency; $S, E$ start and end of stages

could be considered as stable and unaffected by the duration of the contraction itself.

2. Inter-contraction: the mean iso-EMG values noted during the different post-stage contractions were compared. For this analysis only sequences considered as stable by the intra-contraction analysis were used. 
Intra-contraction data. The results of processing these data are given in Table 1. The intra-contraction comparisons for each of the iso-iEMG data showed significant differences between $\mathrm{S}$ and $\mathrm{E}$ of the contraction. For example, the iso-iEMG noted at the 7 th $\mathrm{s}$ after the $20 \mathrm{~km} \cdot \mathrm{h}^{-1}$ run was significantly higher than the one observed during the first $5 \mathrm{~s}$. According to paired Student's $t$-tests a significant increase was usually noted from the 5 th $\mathrm{s}$ after the 14,18 and $20 \mathrm{~km} \cdot \mathrm{h}^{-1}$ running stages. These results suggest that the iso-iEMG for the first $4 \mathrm{~s}$ of each contraction could be considered as stable. This was not the case for two points in the analysis after the $10 \mathrm{~km} \cdot \mathrm{h}^{-1}$ stage, 1 st versus 4 th $\mathrm{s}$ and after the $18 \mathrm{~km} \cdot \mathrm{h}^{-1}$ stages, $2 \mathrm{nd}$ versus $3 \mathrm{rd} \mathrm{s}$ but these increases in the iso-iEMG were not maintained: in each case a decrease was observed the second after.

Inter-contraction data. Figure 3 shows that the isoiEMG obtained during successive holds did not change in any significant way until after the highest intensity run $\left(20 \mathrm{~km} \cdot \mathrm{h}^{-1}\right)$ : the mean value was then greater than after the $18 \mathrm{~km} \cdot \mathrm{h}^{-1}$ stage. The iso-iEMG threshold was therefore localized at post-stage 18 .

From Fig. 3 it can be noted that no intra-contraction variation was observed in iso-MPF. Accordingly an inter-contraction comparison made with the values obtained from the all of the processed signals. The mean MPF were calculated from the 13 samples processed for each isometric contraction. No significant difference was noted during this protocol although a slight decrease in MPF was observed during the last isometric contraction [values after 18 and $20 \mathrm{~km} \cdot \mathrm{h}^{-1}$ running stages: 74.92 (SD 9.5) $\mathrm{Hz}$ and 72.53 (SD 10.5) Hz, respectively].

\section{Run-integrated electromyogram}

The EMG data collected during the different running stages were analysed in order to study changes in the iEMG parameter between treadmill sessions (inter-stage analysis) and during each session (intra-stage analysis) (Fig. 3).

Inter-stage analysis. This analysis was done by comparing the results obtained during the successive stages. These comparisons were made by using the data collected at $\mathrm{S}$ or $\mathrm{E}$ of each stage.

For both $\mathrm{S}$ and $\mathrm{E}$ we noted an increase in the runiEMG in relation to treadmill velocity. [This could be considered as a linear relationship: the correlation coefficients $(r)$ were 0.95 and 0.96 for $\mathrm{S}$ and $\mathrm{E}$ respectively]. However, this increase was not consistent according to paired Student's $t$-test: the first inter-stage differences for data recorded occurred between 14 and 16 and between 10 and $12 \mathrm{~km} \cdot \mathrm{h}^{-1}$ for the results obtained at $\mathrm{S}$ and $\mathrm{E}$ of the stages, respectively (Table 2).

A systematic significant inter-stage increase detected between the last stages $\left(16 \mathrm{vs} 18 \mathrm{~km} \cdot \mathrm{h}^{-1}-\mathrm{E}\right)$ and $(18 \mathrm{vs}$ $20 \mathrm{~km} \cdot \mathrm{h}^{-1}-\mathrm{S}$ and $\mathrm{E}$ ) involved a greater increase in the run-iEMG at the end of the incremental test. Therefore the run-iEMG ( $\mathrm{S}$ and $\mathrm{E})$-velocity relationships were strongly fitted by a second-order polynomial function $(\mathrm{S}, y=1.56$

Table 1 Integrated myoelectrical signal (iEMG) observed during the isometric protocol for each post-stage standard test (PSST) (50\% isometric maximal voluntary contraction). iEMG values were related to iso-EMG obtained for the 1 st s $50 \%$ IMVC performed before the running test

\begin{tabular}{|c|c|c|c|c|c|c|c|c|}
\hline & & \multicolumn{7}{|c|}{ Time of isometric contraction (s) } \\
\hline & & 1st & 2nd & $3 \mathrm{rd}$ & 4th & 5 th & 6th & 7th \\
\hline PSST 10 & $\begin{array}{l}\text { mean } \\
\mathrm{SD}\end{array}$ & $\begin{array}{l}1.09 \\
0.12\end{array}$ & $\begin{array}{l}1.06 \\
0.15\end{array}$ & $\begin{array}{l}1.1 \\
0.13\end{array}$ & $\begin{array}{l}1.13 \\
0.12 \\
* 1\end{array}$ & $\begin{array}{l}1.08 \\
0.13\end{array}$ & $\begin{array}{l}1.11 \\
0.19\end{array}$ & $\begin{array}{l}1.17 \\
0.17 \\
* 1,2,5\end{array}$ \\
\hline PSST 12 & $\begin{array}{l}\text { mean } \\
\text { SD }\end{array}$ & $\begin{array}{l}1.09 \\
0.16\end{array}$ & $\begin{array}{l}1.1 \\
0.15\end{array}$ & $\begin{array}{l}1.06 \\
0.09\end{array}$ & $\begin{array}{l}1.12 \\
0.18\end{array}$ & $\begin{array}{l}1.08 \\
0.19\end{array}$ & $\begin{array}{l}1.25 \\
0.31 \\
* 1,2,5\end{array}$ & $\begin{array}{l}1.27 \\
0.45 \\
* 1,2\end{array}$ \\
\hline PSST 14 & $\begin{array}{l}\text { mean } \\
\text { SD }\end{array}$ & $\begin{array}{l}1.09 \\
0.17\end{array}$ & $\begin{array}{l}1.1 \\
0.19\end{array}$ & $\begin{array}{l}1.07 \\
0.2\end{array}$ & $\begin{array}{l}1.06 \\
0.12\end{array}$ & $\begin{array}{l}1.12 \\
0.14\end{array}$ & $\begin{array}{l}1.16 \\
0.2 \\
* 4\end{array}$ & $\begin{array}{l}1.11 \\
0.17 \\
* 2,3,4\end{array}$ \\
\hline PSST 16 & $\begin{array}{l}\text { mean } \\
\text { SD }\end{array}$ & $\begin{array}{l}1.07 \\
0.1\end{array}$ & $\begin{array}{l}1.11 \\
0.11\end{array}$ & $\begin{array}{l}1.09 \\
0.08\end{array}$ & $\begin{array}{l}1.1 \\
0.12\end{array}$ & $\begin{array}{l}1.17 \\
0.17\end{array}$ & $\begin{array}{l}1.15 \\
0.21\end{array}$ & $\begin{array}{l}1.21 \\
0.18 \\
* 3\end{array}$ \\
\hline PSST 18 & $\begin{array}{l}\text { mean } \\
\mathrm{SD}\end{array}$ & $\begin{array}{l}1.12 \\
0.14\end{array}$ & $\begin{array}{l}1.09 \\
0.15\end{array}$ & $\begin{array}{l}1.16 \\
0.14\end{array}$ & $\begin{array}{l}1.14 \\
0.17\end{array}$ & $\begin{array}{l}1.21 \\
0.19 \\
* 2\end{array}$ & $\begin{array}{l}1.21 \\
0.24\end{array}$ & $\begin{array}{l}1.24 \\
0.1 \\
* 1,2,4\end{array}$ \\
\hline PSST 20 & $\begin{array}{l}\text { mean } \\
\text { SD }\end{array}$ & $\begin{array}{l}1.19 \\
0.15\end{array}$ & $\begin{array}{l}1.16 \\
0.11\end{array}$ & $\begin{array}{l}1.19 \\
0.07\end{array}$ & $\begin{array}{l}1.21 \\
0.08\end{array}$ & $\begin{array}{l}1.24 \\
0.1 \\
* 2\end{array}$ & $\begin{array}{l}1.26 \\
0.1 \\
* 2\end{array}$ & $\begin{array}{l}1.33 \\
0.1 \\
* 1,2,3,4,5\end{array}$ \\
\hline
\end{tabular}

* Significant difference $P<0.05$ (paired Student $t$-test) between iEMG in the column and those at the time indicated in italic 
Table 2 Integrated electromyographic signal observed during the incremental running protocol (run-iEMG) and the results of statistical comparisons. The data are expressed as the quotient iEMG/ burst duration. S, E data recorded at the start (S) and the end (E) of each stage. (Thres Threshold, $n s$ not significant)

\begin{tabular}{|c|c|c|c|c|c|c|}
\hline \multicolumn{7}{|c|}{ Run-iEMG (S) } \\
\hline Mean & 1.01 & 1.17 & 1.2 & 1.38 & 1.49 & 1.88 \\
\hline SD & 0.12 & 0.12 & 0.2 & 0.16 & 0.22 & 0.46 \\
\hline 10 & & ns & $*$ & * & $*$ & * \\
\hline 12 & & & Thres & * & * & * \\
\hline 14 & & & & * & * & * \\
\hline 16 & & & & & ns & * \\
\hline 18 & & & & & & $*$ \\
\hline \multicolumn{7}{|c|}{ Run-iEMG (E) } \\
\hline Mean & 1 & 1.26 & 1.34 & 1.43 & 1.76 & 2.17 \\
\hline SD & 0.08 & 0.27 & 0.21 & 0.18 & 0.28 & 0.41 \\
\hline 10 & & $*$ & * & * & * & * \\
\hline 12 & & & $\mathrm{~ns}$ & ns & * & * \\
\hline 14 & & & & ns & * & * \\
\hline 16 & & & & & $*$ & * \\
\hline 18 & & & & & & $*$ \\
\hline
\end{tabular}

\begin{tabular}{llllll}
\hline \multicolumn{2}{l}{ Run-iEMG (S vs E) } & \multicolumn{3}{l}{} \\
ns & ns & ns & ns & $*$ & $*$ \\
\hline 10 & 12 & 14 & 16 & 18 & 20 \\
Treadmill velocity $\left(\mathrm{km} \cdot \mathrm{h}^{-1}\right)$ & & \\
\hline
\end{tabular}

* Significant difference $P<0.05$ (paired Student $t$-test)

$-0.11 x+0.006 x^{2}, r=0.98 ; \mathrm{E}, y=1.55-0.12 x^{2}$, $r=0.98$, where $y=$ run-iEMG and $x=$ velocity).

Intra-stage analysis. The intra-stage analysis consisted in comparing the run-iEMG observed at $\mathrm{S}$ and $\mathrm{E}$ of the same stage. This paired Student $t$-test (Table 2; runiEMG $\mathrm{S}$ vs E) showed that run-iEMG remained unchanged for the first four stages. The only significant increases were noted during the 18 and $20 \mathrm{~km} \cdot \mathrm{h}^{-1}$ stages. Therefore, it was considered that the run-iEMG threshold occurred at $16 \mathrm{~km} \cdot \mathrm{h}^{-1}$ (Fig. 3).

\section{Rating of perceived exertion}

According to the statistical analysis, RPE increased significantly in the last isometric contraction (i.e. poststage $20 \mathrm{~km} \cdot \mathrm{h}^{-1}$ ). The RPE threshold was determined at $18 \mathrm{~km} \cdot \mathrm{h}^{-1}$ (Fig. 3).

\section{Threshold chronology}

A threshold chronology can be established (Fig. 3): the lactate and respiratory equivalent for oxygen thresholds were the first to be detected after a phase where the different parameters considered were unchanged (from 10 to $14 \mathrm{~km} \cdot \mathrm{h}^{-1}$ ). The respiratory equivalent for carbon dioxide threshold appeared at $16 \mathrm{~km} \cdot \mathrm{h}^{-1}$ and co- incided with the run-iEMG threshold. The iso-iEMG was later (post-stage 18) and occurred at the same time as the RPE threshold for the isometric effort.

However, the parallel change of $\dot{V}_{\mathrm{E}}$ and run-iEMG relative to velocity noted during the incremental test must be underlined. (This is also expressed by a significant linear relationship between these parameters: $r=0.95$ and 0.97 for S- and E-run-iEMG $/ \dot{V}_{\mathrm{E}}$, respectively).

\section{Discussion}

Even before any change in metabolism appeared (the first three stages) the run-EMG and the $\dot{V}_{\mathrm{E}}$ increased in relation to running velocity. These changes were not related either to changes in blood lactate concentration or to the appearance of the respiratory equivalent thresholds: no significant change in lactate concentration and in respiratory equivalent appeared before $14 \mathrm{~km} \cdot \mathrm{h}^{-1}$ [changes in $\dot{V}_{\mathrm{E}}$ and EMG (E-run-iEMG) were noted as early as the comparison between the 10 and $12 \mathrm{~km} \cdot \mathrm{h}^{-1}$ stages]. Therefore, the increase in $\dot{V}_{\mathrm{E}}$ observed during these first stages would not seem to be linked to a humoral type regulation but to a central or reflex neurogenic regulation (reflex triggered by muscular mechanoreceptor stimulation) involving both ventilatory and muscle activities.

The problem, then, is to identify the effects of regulation linked to an increase in exercise intensity and those arising from a change in metabolic conditions during an incremental running test.

In the case of ventilatory parameters, the changes in ventilatory equivalents $\left(\dot{V}_{\mathrm{E}} / \dot{V} \mathrm{O}_{2}\right.$ and $\left.\dot{V}_{\mathrm{E}} / \dot{V} \mathrm{CO}_{2}\right)$ can be considered as indications of metabolic changes which have been interpreted as evidence of acidaemia (Wasserman et al. 1990) or as a sign of $\mathrm{K}^{+}$accumulation (Busse et al. 1991). The results of the statistical analyses enable us to pinpoint the $\dot{V}_{\mathrm{E}} / \dot{V} \mathrm{O}_{2}$ and $\dot{V}_{\mathrm{E}} / \dot{V} \mathrm{CO}_{2}$ thresholds at 14 and $16 \mathrm{~km} \cdot \mathrm{h}^{-1}$ respectively.

Considering the EMG breakpoint, it is difficult to know how to discriminate the role played by an increase in exercise intensity from the one played by fatigue (see Viitasalo and Komi 1978). The detection of an EMG breakpoint has often been interpreted as a sign of type II fibre recruitment during an incremental test (Hélal et al. 1987; Mateika and Duffin 1994; Nagata et al. 1981). Nevertheless, this breakpoint may appear:

1. With no state of fatigue: the action potentials in type II fibres being more important, contributing to the relative increase in the EMG signal (see Tanji and Kato 1973).

2. In a state of fatigue: the newly recruited fibres for stages requiring a great deal of power become fatigued quickly (fast glycolytic fibres). This great fatigability can cause the recruitment of additional motor units in order to maintain the required power at the same stage. 
However, a breakpoint in the EMG-exercise intensity relationship has not always been detected, whether it be with no influence of fatigue (Goto et al. 1976), or under the effect of fatigue during an incremental exercise test leading to exhaustion (Taylor and Bronks 1995).

The contradiction in these observations has led us to be cautious in the conclusions relating the type of fibres recruited with respect to the characteristics of the EMGexercise intensity relationship.

Conversely, for a given stage, it can be stated that an increase in EMG is the result of the additional recruitment of fibres. However, this does not imply that this breakpoint indicates the activation threshold of those type II fibres. Some of these type II fibres may already have been activated at one or several earlier stages although they have shown no sign of fatigue at that time. This phenomenon is even more likely concerning our group of subjects since they were well trained and were able to develop fully the oxidative potential of their type II fibres (Henriksson and Reitman 1977).

Because of all these reasons we did not choose to make a direct analysis of the changes in the EMG signal in relation to velocity to detect fatigue onset. Our method was based on observations by Miyashita et al. (1981), who have found that the EMG was constant during the low or medium power stages of a 10-min fixed-rate intensity test. However, the EMG increased at higher power outputs, from the first minutes of exercise, indicating neuromuscular fatigue.

To determine the EMG threshold, the first occurrence of an increase in the level of electrical activity must be identified. The duration of our stages (4 min) was chosen so as to be long enough to come over the ventilatory adaptation inertia phenomena and to observe the increase in the activity level (see Miyashita et al. 1981).

According to these analyses the run-iEMG remained constant during the first four stages $\left(10-16 \mathrm{~km} \cdot \mathrm{h}^{-1}\right.$, i.e. $62 \%-83 \%\left(\dot{V} \mathrm{O}_{2 \max }\right)$. The first stage $\left(18 \mathrm{~km} \cdot \mathrm{h}^{-1}\right)$ where the run-iEMG increased significantly during the 4-min run corresponded to the one where the $\dot{V}_{\mathrm{E}} / \dot{V} \mathrm{CO}_{2}$ value also increased. These different increases were confirmed at the $20 \mathrm{~km} \cdot \mathrm{h}^{-1}$ stage.

To avoid muscle activation processes related to an increase in exercise power a standard isometric contraction of the knee extensors was performed just after each running stage. These standard tests were carried out at $50 \%$ of IMVC, supposing this contraction level to be high enough to be sensitive to prior run exertion and low enough to be maintained for $10 \mathrm{~s}$ throughout the experiment in accordance with the findings of ArendtNielsen and Mills (1988), who have demonstrated that this contraction level can be maintained for $50 \mathrm{~s}$ without decline. The $50 \% \mathrm{IMVC}$ is also, according to Duchêne and Goubel (1993), the force level from which the changes in EMG signal spectrum parameter can be more systematically observed.

For the standard tests, the changes in the EMG signal were later than all those discussed above. Only a significant increase in iso-iEMG appeared during the test carried out after the last stage reached by the subjects (iso-iEMG threshold: $18 \mathrm{~km} \cdot \mathrm{h}^{-1}$ ) while the spectrum parameters showed no significant changes.

The stability in EMG noted during the isometric contraction, and during the period averaging about $15 \mathrm{~s}$ following the end of stages $10-18 \mathrm{~km} \cdot \mathrm{h}^{-1}$ of the running protocol, would imply all the more so that it would also have been stable if tested 45 s later (i.e. at the end of the inter-stage rest time). Thus the iEMG noted at $\mathrm{S}$ of each stage may be considered to have been determined by exercise intensity and not affected by fatigue. On the basis of these results the iEMG-treadmill velocity relationship obtained at $\mathrm{S}$ of the stage represents the strict EMG-intensity relationship. Consequently, the increase in the iEMG noted during the same stage can be seen as a sign of local neuromuscular fatigue. The analyses of EMG changes recorded during the running and isometric protocols can therefore be considered as complementary.

The main purpose of the method applied in this study was to identify a relative instability not only in the EMG parameters but also in the ventilatory ones by taking into account variations in respiratory equivalents. We have seen that different methods have been used to identify these breakpoints. These differences in the methods used in the same experiment can lead to distortion because the different tests have different sensitivities. To solve this problem all our data were processed in the same way, based on variations observed at group level rather than individually and the same method was applied whatever the nature of the parameter to be analysed. This procedure requires a homogeneous experimental group, which explains why we chose welltrained athletes of similar ability: all the subjects were able to finish the incremental test at the same stage $\left(20 \mathrm{~km} \cdot \mathrm{h}^{-1}\right)$ with limited inter-individual variation in $\left(\dot{V} \mathrm{O}_{2 \max }\right)$ [72.3 (SD 5) $\left.\mathrm{ml} \cdot \mathrm{min}^{-1} \cdot \mathrm{kg}^{-1}\right]$. However, as Taylor and Bronks (1995) have found, there was a greater inter-individual variability in the EMG parameters. The run-iEMG values reached at the last stage were 1.88 (SD 0.47) and 2.17 (SD 0.42) at S and $\mathrm{E}$ of the stage, respectively (values normalized relative to the first stage).

The results obtained and shown in an exercise intensity continuum revealed that the lactacidaemia and $\dot{V}_{\mathrm{E}} / \dot{V} \mathrm{O}_{2}$ thresholds both occurred at $14 \mathrm{~km} \cdot \mathrm{h}^{-1}$. The $14 \mathrm{~km} \cdot \mathrm{h}^{-1}$. stage, where the level of lactacidaemia reached $2.6(\mathrm{SD} 0.3) \mathrm{mmol} \cdot 1^{-1}$ while the $\dot{V}_{\mathrm{E}} / \dot{V} \mathrm{O}_{2}$ was still constant, would correspond to the limit of the aerobic phase. The intra-stage constancy of the run-iEMG signal could be considered as a sign of metabolic equilibrium. The $16 \mathrm{~km} \cdot \mathrm{h}^{-1}$ stage, where the respiratory equivalent for $\dot{V}_{\mathrm{E}} / \dot{V} \mathrm{O}_{2}$ increased significantly while the respiratory equivalent for the $\dot{V}_{\mathrm{E}} / \dot{V} \mathrm{CO}_{2}$ was still constant, would correspond to the isocapnic buffering allowing suitable metabolic conditions for muscular contractions to be maintained. An intra-stage constancy in run-iEMG was noted for this stage where the lactacidaemia was close to $4 \mathrm{mmol} \cdot 1^{-1}$. Above this stage, 
(from 18 to $20 \mathrm{~km} \cdot \mathrm{h}^{-1}$ ), the buffering system would have been weakened leading to a deterioration in the metabolic conditions for contractions. These phenomena were simultaneous with the intra-stage increase in the run-iEMG signal.

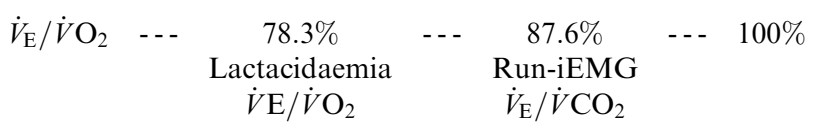

These results show a later iEMG threshold than has been noted by Viitasalo et al. (1985) or Sihvonen et al. (1988). For these authors, the iEMG threshold during a cycle ergometer incremental exercise test was simultaneous with the lactic acid and ventilatory thresholds (respiratory equivalent for $\dot{V}_{\mathrm{E}} / \dot{V} \mathrm{O}_{2}$ ). Mateika and Duffin (1994) have recorded an iEMG threshold appearing earlier than the first ventilatory threshold. However, for other authors such as Nagata et al. (1981), Moritani et al. (1993) and Taylor and Bronks (1994), the iEMG threshold has occurred after the first ventilatory threshold.

The distinctive feature of our results, i.e. the late occurrence of the iEMG threshold, can be explained by the method chosen, which allowed us to minimize the effect of the exercise power. The fact that the iEMG threshold appeared later on is perhaps, within the framework of our experiment, due to the characteristics of the subjects studied. They were well-trained athletes specializing in the activity in which they were evaluated (recall their high $\dot{V} \mathrm{O}_{2 \max }$ values). Their level of training provided them with good respiratory control and they were able to adapt well both from a general and local viewpoint.

These observations, made after having minimized the effect of the increase in exercise power, confirm the fact that humoral factors influence both ventilation mechanisms and muscle contraction processes. The main factors are probably "a decrease in muscle $\mathrm{pH}$ and elevated extracellular potassium concentration" as stated by Vogiatzis et al. (1996). The fall in muscle $\mathrm{pH}$ causing inhibition in metabolic regulation as well as a decrease in the excitability of the muscle cell leads to a decrease in the mechanical effect of the contraction. Thus, to maintain a particular force level more motor units must be recruited. This fall in muscle $\mathrm{pH}$, leading to a fall in blood $\mathrm{pH}$ also acts indirectly on the arterial chemoreceptors linked to ventilation regulating mechanisms. The intra-cellular acidosis has also been favoured by a fall in intercellular $\left[\mathrm{K}^{+}\right]$that can reach $10-20 \%$ in VL after an exhausting exercise (Sjogaard 1986). Moreover, the variations in $\left[\mathrm{K}^{+}\right]$themselves represent a stimulus. The cellular variations in $\left[\mathrm{K}^{+}\right]$stimulate muscular chemosensitive groups III and IV nerve fibres, and similarly have been shown to take part in ventilation regulation (Vogiatzis et al. 1996). It has been suggested that this action is probably strengthened by the stimulation of arterial chemoreceptors (Paterson and Nye 1991). Thus, the variations in $\left[\mathrm{K}^{+}\right]$are ventilation regulating stimuli by reflex loops different to those responding to $\mathrm{pH}$. This suggests a strong relationship between $\dot{V}_{\mathrm{E}}$ and $\left[\mathrm{K}^{+}\right]$, as has been reported by Busse et al. (1991).

However, the conclusion about the comparative timecourses of the different parameters must be regarded with caution. It is important to underline the difference in the measurement frequency of these parameters (see Mateika and Duffin 1994) and the different diffusion speeds and the delays between the intra- and extra-cellular phenomena. Finally, as in most other experiments of this nature, our results are based on EMG of VL. It seems necessary to check these results against muscles recruited differently during a running protocol to have a more general view of the neuromuscular fatigue threshold.

Acknowledgements We would like to thank Dr E. Joussellin for his medical assistance, M. Thomaidis and L. Caplan for their technical participation and $\mathrm{S}$. Kloc for translating and proof-reading this article.

\section{References}

Arendt-Nielsen L, Mills KR (1988) Muscle fiber conduction velocity, mean power frequency, mean voltage and force during submaximal fatiguing contractions of human quadriceps. Eur $\mathbf{J}$ Appl Physiol 58:20-25

Borg G (1970) Perceived exertion as an indicator of somatic stress. Scand J Rehabil Med 2-3:92-98

Busse MW, Maasen N, Konrad H (1991) Relation between plasma $\mathrm{K}+$ and ventilation during incremental exercise after glycogen depletion and repletion in man. J Physiol 443:469-476

Conconi F, Ferrari M, Ziglio P, Codeca L (1982) Determination of the anaerobic threshold by a noninvasive field test in runners. J Appl Physiol 52:869-873

Davis HA, Basset J, Hughes P, Gass GC (1983) Anaerobic threshold and lactate turnpoint. Eur J Appl Physiol 50:383-392

Davis JA (1985) Anaerobic threshold: review of the concept and directions for future research. Med Sci Sports Exerc 17:6-18

De Vries HA, Housh TJ, Johnson GO, Evans SA, Tharp GO, Housh DJ, Hugues RA (1990) Factors affecting the estimation of physical working capacity at the fatigue threshold. Ergonomics 33:25-33

Duchêne J, Goubel F (1993) Surface electromyogram during voluntary contraction: processing tools and relation to physical events. Crit Rev Biomed Eng 21:297-313

Enoka RM, Stuart DG (1992) Neurobiology of muscle fatigue. J Appl Physiol 72:1631-1648

Goto S, Toyoshima S, Hoshihana T (1976) Study of the integrated EMG of big muscles during pedalling at various loads, frequency and equivalent power. In: Komi PV (ed) Biomechanics VA. University Park Press, Baltimore, Md., pp 246-256

Hägg GM (1992) Interpretation of EMG spectral alterations and alterations indexes at sustained contraction. J Appl Physiol 73:1211-1217

Hélal JN, Guezennec CY, Goubel F (1987) The aerobic-anaerobic transition: re-examination of the threshold concept including an electromyographic approach. Eur J Appl Physiol 5:643-649

Henriksson J, Reitman JS (1977) Time course of activity changes in human skeletal muscle succinate dehydrogenase and cytochrome oxidase with physical activity and inactivity. Acta Physiol 99:91-97

Lippold OCJ (1952) The relation between integrated action potentials in a human muscle and its isometric tension. J Physiol 117:492-499

Mader A, Liesen H, Heck T, Philip H, Rost R, Schurch P, Hollmann W (1976) Zur Beurteilung der Sportartspezifischen 
Ausdauer Leistungsbewertung und Trainingsgestaltung. Dtsch Z Sports Med 30:212-218

Mateika JH, Duffin J (1994) Coincidental changes in ventilation and electromyographic activity during consecutive incremental exercise tests. Eur J Appl Physiol 68:54-61

Miyashita M, Kanehisa H, Nemoto I (1981) EMG related to anaerobic threshold. J Sports Med 21:209-217

Moritani T, Takaishi T, Matsumoto T (1993) Determination of maximal power output at neuromuscular fatigue threshold. J Appl Physiol 74:1729-1734

Nagata A, Muro M, Moritani T, Yoshida T (1981) Anaerobic threshold determination by blood lactate and myoelectric signals. Jpn J Physiol 31:587-597

Nilsson J, Thorstensson A (1987) Adaptability in frequency and amplitude of leg movements during human locomotion at different speeds. Acta Physiol Scand 129:107-114

Paterson DJ, Nye PCG (1991) Effect of oxygen and potassiumexcited ventilation in the decerebrate cat. Respir Physiol $84: 223-230$

Sihvonen T, Airaksinen O, Hanninen O (1988) Electrical behaviour (rms-EMG) of frontalis muscle during incremental exercise. Acta Physiol Scand 134 [Suppl 575]:140

Sjogaardt G (1986) Water and electrolyte fluxes during exercise and their relation to fatigue. Acta Physiol Scand 128 [Suppl 556]:129-136
Tanji J, Kato M (1973) Recruitment of motor units in voluntary contraction of a finger in man. Exp Neurol 40:759-770

Taylor AD, Bronks R (1994) Electromyographic correlates of the transition from aerobic to anaerobic metabolism in treadmill running. Eur J Appl Physiol 69:508-515

Taylor AD, Bronks R (1995) Reproducibility and validity of the quadriceps muscle integrated electromyogram threshold during incremental cycle ergometry. Eur J Appl Physiol 70:252-257

Viitasalo JT, Komi PV (1978) Interrelationships of EMG signal characteristics at different levels of muscle tension and during fatigue. Electromyogr Clin Neurophysiol 18:167-178

Viitasalo JT, Luhtanen P, Rahkila P, Rusko H (1985) Electromyographic activity related to aerobic and anaerobic threshold in ergometer bicycling. Acta Physiol Scand 124:287-293

Vogiatzis I, Spurway NC, Jennett S, Wilson J, Sinclair J (1996) Changes in ventilation related to changes in electromyograph activity during repetitive bouts of isometric exercise in simulated sailing. Eur J Appl Physiol 72:195-203

Wasserman K (1984) The anaerobic threshold measurement to evaluate exercise performance. Am Rev Respir Dis 129 [Suppl]:S35-S40

Wasserman K, Beaver WL, Whipp BJ (1990) Gas exchange theory and the lactic acidosis (anaerobic) threshold. Circulation 81 [Supp 2]:14-30 